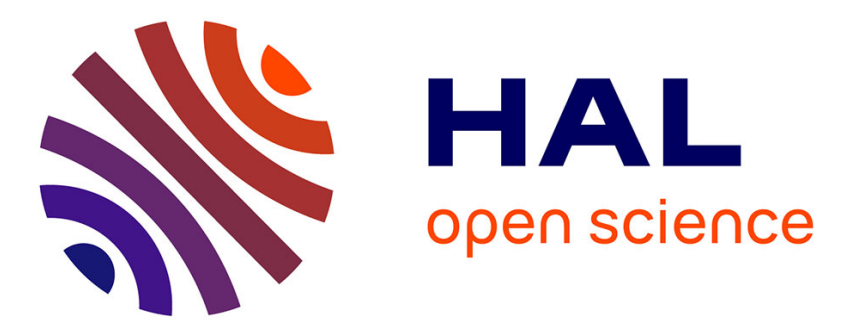

\title{
Stable isotopes reveal food web modifications along the upstream-downstream gradient of a temperate stream
}

\author{
N. Hette Tronquart, J. Belliard, E. Tales, T. Oberdorff
}

\section{To cite this version:}

N. Hette Tronquart, J. Belliard, E. Tales, T. Oberdorff. Stable isotopes reveal food web modifications along the upstream-downstream gradient of a temperate stream. Aquatic Sciences - Research Across Boundaries, 2016, 78 (2), pp.255-265. 10.1007/s00027-015-0421-8 . hal-01398416

\section{HAL Id: hal-01398416 https://hal.science/hal-01398416}

Submitted on 17 Nov 2016

HAL is a multi-disciplinary open access archive for the deposit and dissemination of scientific research documents, whether they are published or not. The documents may come from teaching and research institutions in France or abroad, or from public or private research centers.
L'archive ouverte pluridisciplinaire HAL, est destinée au dépôt et à la diffusion de documents scientifiques de niveau recherche, publiés ou non, émanant des établissements d'enseignement et de recherche français ou étrangers, des laboratoires publics ou privés. 
1 This is an earlier view of the accepted manuscript for the article "Stable isotopes reveal food web modifications

2 along the upstream-downstream gradient of a temperate stream". The final publication is available at:

3 http://link.springer.com/article/10.1007\%2Fs00027-015-0421-8

4 
Nicolas Hette-Tronquart*a ${ }^{\mathrm{a}}$, Jérôme Belliard ${ }^{\mathrm{a}}$, Evelyne Tales ${ }^{\mathrm{a}}$ and Thierry Oberdorff ${ }^{\mathrm{b}}$.

\section{6}

${ }^{\text {a }}$ Irstea, UR HBAN, 1 rue Pierre-Gilles de Gennes, CS 10030, F-92761 Antony, France

10 underlies food web modifications.

32

${ }^{\mathrm{b}}$ UMR CNRS 7208-IRD 207-MNHN-UPMC-UNICAEN "Biologie des Organismes et Ecosystemes Aquatiques", Museum National d'Histoire Naturelle, 43 rue Cuvier 75005 Paris, France

* Correspondence to: Nicolas Hette-Tronquart, E-mail: nicolas.hette@edu.mnhn.fr, Phone: +33 (0)1 409661 21, Fax: +33 (0)1 40966199

\section{Abstract:} to both structural and functional changes. The structural change was mainly related to an increase in species the functional features of the web directly, without changing the web composition. The proposed framework structural changes to a generalist feeding strategy. The framework highlights the benefits of conducting the

Stable isotopes reveal food web modifications along the upstream-downstream gradient of a temperate stream.

The upstream-downstream gradient (UDG) is a key feature of streams. For instance food webs are assumed to change from upstream to downstream. We tested this hypothesis in a small European river catchment $\left(937 \mathrm{~km}^{2}\right)$, and examined whether food web modifications are related to structural (i.e. food web composition) or functional changes (i.e. alteration of linkagess within the web). We adopted a double approach at two levels of organisation (assemblage and species levels) using two isotopic metrics (isotopic space area and isotopic niche overlap), and proposed a new hypothesis-testing framework for exploring the dominant feeding strategy within a food web.

We confirmed that the UDG influenced stream food webs, and found that food web modifications were related richness, and induced functional modifications of the web (indirect effect). In addition, the UDG also modified allowed relating the direct effect of the UDG to a diet specialisation of the species, and the indirect effect via the double approach, and provides a foundation for future studies investigating the dominant feeding strategy that 


\section{Introduction:}

In most streams water volume, flow velocity, and sediment size vary from upstream to downstream reaches in a generally progressive fashion (Petts and Calow 1996). All these changes in physical conditions make up the upstream-downstream gradient (UDG), also called longitudinal or fluvial gradient (Costas and Pardo 2014, Winemiller at al. 2011). Along this gradient food webs are susceptible to change (Power and Dietrich 2002). Like Holt (1996) we distinguished changes related to structural and functional features of food webs.

Food web structure is related to the members making up the web, i.e. resources or consumers. In streams, biological communities are known to respond, at least partly, to the upstream-downstream modifications in abiotic environmental conditions (Rice et al. 2001) and change accordingly (e.g. Verneaux et al. 2003, Tomanova et al. 2007 for macroinvertebrates in temperate and tropical streams, respectively; Belliard et al. 1997, Ibañez et al. 2007 for fish in temperate and tropical streams, respectively). Sources of organic matter are also supposed to change (Vannote et al. 1980, but see Sedell et al. 1989 for large rivers), so that the whole food web structure (resources and consumers) is susceptible to change along the UDG.

Functional features of food webs are related to the linkages among the members of the web (e.g. number, kind or intensity of the linkages). These trophic interactions can be affected by structural modifications of the web (e.g. changes in species richness, Post and Takimoto 2007), but can also be modified while the food web structure remains unchanged (e.g. change of the dietary regime of some consumers without changes in resources or consumers, Holt 1996). Along the UDG, a change in dietary regime can be due to the longitudinal changes in hydrologic variability (Sabo et al. 2010), habitat volume (MacGarvey and Hughes 2008) and/or heterogeneity (Townsend and Hildrew 1994), because these modifications of environmental conditions potentially affect energy requirements of individuals, resource availability or inter- and intra-specific competition.

To date, even if some studies have already focused on the influence of the UDG on stream food webs (e.g. Winemiller at al. 2011; Chang et al. 2012; Costas and Pardo 2014), the nature of its effect remains poorly documented. Notably, no study has assessed whether the effect of UDG on food webs is mainly structural or functional (or both). In this study we deal with this specific issue focusing on fish assemblages. We used fish because they are known to display various feeding behaviours covering a wide range of trophic levels (from herbivorous and/or detritivorous to piscivorous species) and a wide range of basal resources (from autochthonous to terrestrial organic matter) (Matthews 1998; Jepsen and Winemiller 2002; Oberdorff et al. 
64

2002). As such, fish assemblages constitute a substantial part of stream food webs and can be used as a model for testing basic hypotheses on food web functioning. We assess structural modifications using fish assemblage composition, species richness and density of individuals. Using stable isotopes of carbon and nitrogen, we evaluate functional modifications with a double approach based on two metrics (i.e. the isotopic space area and the isotopic niche overlap, see Definition box) related to two levels of organisation (i.e. assemblage and species levels, respectively).

The double approach seems necessary to determine the dominant assemblage feeding strategy associated with the observed food web modification. Three non-exclusive feeding strategies having different implications in terms of stable isotope signals, are listed by Bearhop et al. (2004): (1) specialist species (i.e. all individuals of the species are specialised on the same food type), (2) type A generalist species (i.e. all individuals of the species are taking a wide range of food types), or (3) type B generalist species (i.e. each individual of the species is specialising on different but narrow range of food types). Basically, the stable isotope signal of an individual is the average signal of its diet items (integration in space and time of the signals Rasmussen et al. 2009; Vander Zanden and Rasmussen 1999). From this basic principle we deduce that: (1) individuals should display highly variable signals among different specialist species (large isotopic space area), but very similar signals within a specialist species (low isotopic niche overlap); (2) individuals should display very similar signals among and within different type A generalist species (small isotopic space area and high isotopic niche overlap respectively); and (3) individuals from type B generalist species should display highly variable signals (large isotopic space area) but a similar range of isotopic signals among and within the species (high isotopic niche overlap). The complementary responses of both isotopic metrics led us to propose a hypothesis-testing framework (Fig. 1) that can determine which feeding strategy is predominant in the assemblage to explain the observed food web modification. In this study we first examined the effect of the UDG on food web structure using fish assemblage composition, species richness and density of individuals. We then tested if the UDG modified the functional features of the web using a linear model and the isotopic space area. We conducted a path analysis to determine whether the functional changes were related to a direct effect of the UDG on the trophic linkages, or to an indirect effect induced by structural changes (e.g. modifications of species richness or density of individuals). Finally we completed our analysis by studying the variations of the isotopic niche overlap along the UDG and used both isotopic metrics and our hypothesis-testing framework to determine the feeding strategy of the fish. 


\section{Material and Methods}

\section{Study Sites and estimation of the upstream-downstream gradient (UDG)}

We studied twelve sites located in the catchment of the Orge River $\left(937 \mathrm{~km}^{2}\right)$, a tributary of the Seine River, France (Fig. 2). Within this small catchment, climatic conditions and geology are rather homogeneous (http://www.geoportail.gouv.fr/accueil). Sites were chosen to reflect the upstream-downstream gradient (UDG) and to undergo similar moderate anthropogenic pressures (i.e. mostly forested or agricultural lands with extensive practices). Upstream catchment areas of the sites ranged from 17 to $210 \mathrm{~km}^{2}$ (Fig. 2 and Table 1). Site position along the UDG was quantified using a multivariate combination of four synthetic variables: upstream catchment area $\left(\mathrm{km}^{2}\right)$, distance from the sources $(\mathrm{km})$, and two geomorphological variables (mean stream width (m) and mean water depth (m)). Catchment area and distance from the sources were calculated using data from the Regional Geographic Information System (RGIS) of the "Institut d'Aménagement et d'Urbanisme d'île-deFrance". Stream width was measured at five transects of each sampled site. Water depth was measured at ten transects (five measurements per transect). Stream width and water depth measurements were averaged to obtain one mean value for each site. Data for catchment area and stream width were log-transformed for normality.

Finally, a multivariate index was generated using the first axis of a principal component analysis performed on the four variables ( $85 \%$ of variation explained by the first axis, Table 1); hereafter, we refer to this synthetic variable as the position along the UDG.

\section{Sampling and evaluation of fish species richness and density}

The size of each sampling site varied with stream width (site length was 10 to 20 times the stream width) to encompass complete sets of the characteristic stream form (e.g. pools, riffles and runs: Oberdorff et al. (2001)). The minimal distance between two sites was more than $2 \mathrm{~km}$, and we considered that fish movements among sites remained uncommon (cf. Minns 1995). Fish were sampled during July and August 2009 by conducting a single-pass electrofishing at each site. Species richness of the fish assemblage was the total number of species sampled by electrofishing at a site, while density of individuals within the assemblage was defined as the ratio of the number of all fish found at the site divided by the surface of the sampling area. All fish species were collected for stable isotope analyses (SIA), except those species represented only by a low number of small-sized juveniles. For one site, recently stocked brown trouts (Salmo trutta fario) were discarded from SIA. For the 12 sites, the number of fish species retained for SIA was closely related to assemblage species richness (rho $=0.80$, Spearman's correlation). Whenever possible, a sample consisted of different fin clips from the same 
123

124

125

126

127

128

129

130

131

132

133

134

135

136

137

138

139

140

141

142

143

144

145

146

147

148

149

150

151

152

individual (from 1 to 3 different fins) to avoid killing fish (Hette-Tronquart et al. 2012). However, two species were too small to obtain enough fin tissue for analysis (i.e. Gasterosteus aculeatus and Pungitius pungitius). In this case, individuals were euthanized and analyses were carried out using the whole fish (after removing head and viscera) so that a sample consisted mainly of muscle, fin, and bone tissues. Nonetheless, all fish were handled in accordance with recent ethical standards (American Fisheries Society 2004). After collection, samples were transported on ice to the laboratory, where they were rinsed the same day with distilled water and kept frozen for later handling.

\section{Stable Isotope Analysis (SIA)}

We analysed carbon and nitrogen stable isotope ratios for 465 samples (see Table 2) with a Thermo Electron FlashEA 1112 Series elemental analyser (single reactor setup) coupled with a Thermo Scientific DeltaV Plus Isotope Ratio Mass Spectrometer (EA-IRMS) (Thermo Scientific, Bremen, Germany). Each sample underwent the same preparation prior to analysis. After being freeze-dried, samples were ground to powder and weighed precisely $(500 \pm 10 \mu \mathrm{g})$ in tin capsules. Altogether, isotope analyses were done on eleven fish species (Table 2). Samples were analysed in consecutive sequences (96 samples per sequence), beginning with 3 empty tin capsules for blank correction. Three international reference materials (IAEA CH-7, N1 and N2, International Atomic Energy Agency, Vienna, Austria) were analysed at the beginning and at the end of the sequence for linear normalisation. One internal reference (muscle from Squalius cephalus) was analysed every six samples in order to compensate for possible machine drift and as a quality control measure. Linearity correction was carried out to account for differences in peak amplitudes between sample and reference gases $\left(\mathrm{CO}_{2}\right.$ or $\left.\mathrm{N}_{2}\right)$. Resulting isotope ratios $\mathrm{R}$ (i.e. ${ }^{13} \mathrm{C} /{ }^{12} \mathrm{C}$ and ${ }^{15} \mathrm{~N} /{ }^{14} \mathrm{~N}$ ) were expressed in conventional delta notation ( $\delta$ ), relative to the international standards, Pee Dee Belemnite limestone (V-PDB R $=11180.2 \pm 2.8 \times 10^{-6}$, Werner and Brand 2001), and atmospheric air $\left(\mathrm{R}=3678 \pm 1.5 \times 10^{-6}\right.$, Werner and Brand 2001). With the standard deviation of our internal reference (S. cephalus. muscle) we assessed the analytical precision associated with our sample runs for $\delta^{13} \mathrm{C}$ and $\delta^{15} \mathrm{~N}$ over the whole SIA period (from May 2010 to November 2011), and obtained values of 0.15 and $0.21 \%$, respectively. Lipid correction was carried out for all samples for which the C:N ratio was greater than 3.5 (395 out of the 465 samples), following recommendations and using the equation for aquatic animals proposed in Post et al. (2007). All isotope ratios obtained from fin clip analysis were corrected using the general models developed in Hette-Tronquart et al. (2012) to account for isotope signal differences between fin and muscle tissues. In addition, this correction strongly reduced the influence of different integration times between the 
isotope signals of fin clip and whole body, because all signals were related to muscle tissue after correction.

\section{4}

\section{5}

\section{Determination of the isotopic space area and the isotopic niche overlap}

To test our hypotheses, we first used an assemblage-wide metric of the food web: the isotopic space area occupied by the fish assemblage. The metric is based on the convex hull approach and was adapted from one metric developed by Layman et al. (2007) initially called Total Area - TA - in the publication (see below further explanations on the differences between TA and isotopic space area). Hereafter, we define the isotopic space area as the area of the convex hull encompassing all fish individuals in $\delta^{13} \mathrm{C}-\delta^{15} \mathrm{~N}$ bi-plot space. Like other studies (e.g. O'Neil and Thorp 2014) we chose the convex hull approach instead of the standard ellipse approach (proposed by Jackson et al. 2011) because it includes information on every part of the isotopic space occupied by the assemblage (Layman et al. 2012), which seems more appropriate to measure the isotopic niche overlap (Hammerschlag-Peyer et al. 2011). Given that the isotopic space is closely tied to the trophic space (Newsome et al. 2007; Semmens et al. 2009; Jackson et al. 2011), the isotopic space area (like the TA) occupied by an assemblage gives an integrative measure of the exploited resource diversity (variation in $\delta^{13} \mathrm{C}$ ) and of the trophic level richness (variation in $\delta^{15} \mathrm{~N}$ ) in the assemblage. Knowing the isotopic variability in basal resources, the isotopic space area gives a measure of the trophic diversity displayed by an assemblage. In our case, we checked that the variability of three basal resources (epilithic biofilm, leaf litter and suspended matter) did not display any upstream-downstream pattern (Online Resource 1), and we deduced that the variability of the isotopic space area along the UDG could not be explained by this source of variability. Like the TA, the isotopic space area is a metric strongly influenced by the number of individuals included in the calculation (Syväranta et al. 2013), and Layman et al. (2007) emphasized that "between- and among-system comparisons using community-wide metrics will be most meaningful when food webs are defined in the same fashion". To solve this problem, Layman et al. (2007) proposed calculating the TA with the mean isotope signal of each species within an assemblage. In our case however, we analysed only one or two species at the three most upstream sites, preventing us from calculating a TA from the species' mean isotopic values. Consequently, unlike TA, we chose to calculate the isotopic space area from individual signals. At one of the three sites, only six individuals were analysed, so that we calculated the isotopic space area directly, using this reduced number of individuals. For the other 11 sites, we calculated the isotopic space area according to a three step-method, which was adapted from the bootstrap-method of Jackson et al. (2012). In a first step we randomly chose one individual per species collected at the site. In a second step we randomly selected additional individuals from the remaining pool of 
183 individuals sampled at the site, to obtain ten individuals. In a third step we calculated the isotopic space area

184 occupied by the ten selected individuals. We repeated these three steps 1000 times and obtained the isotopic

185 space area of the site by taking the median of the 1000 calculated areas. Using this bootstrap-method, we

186 strongly reduced the effect of sampling size on the convex hull area, because we had the same number of

187 individuals for all but one site. We were aware that 10 individuals were certainly not sufficient to evaluate the

188 total extent of the realised trophic diversity (Syväranta et al. 2013), but we used the isotopic space areas in a

189 relative way to compare the trophic diversity among our sites. Examining the isotopic space areas, we tested for

190 the potential effects of the UDG at the assemblage level, and we quantified the relationships between the UDG,

191 assemblage species richness, density of individuals within the assemblage, and the isotopic space area by means

192 of a path analysis (Wootton 1994).

193 To go a step further, we also examined the effects of the UDG at the species level, by calculating the

194 isotopic niche overlap of each species. We defined the isotopic niche overlap, as the overlap of the isotopic niche

195 of one species with the isotopic niches of the other species. To obtain the isotopic niche overlap we considered

196 each species for which we had at least five individuals at each site where there were at least two species. First we

197 randomly selected five individuals for each species. Second we determined the niche of each species using the

198 convex hull that encompassed the five individuals. Third, we calculated the isotopic niche overlap of one species

199 as the ratio of the area of its niche occupied by the niches of the other species, divided by the area of its niche

200 (Fig. 3). We repeated these steps 1000 times, and took the median of the resulting distributions to obtain an

201 isotopic niche overlap value for each species at each site. First, we tested if the isotopic niche overlap values

202 were strongly influenced by species identity conducting a Kruskal-Wallis rank sum test. Then, we examined the

203 effects of the UDG, assemblage species richness, assemblage density, and species identity developing a linear

204 model (isotopic niche overlap $\sim$ UDG + species richness + assemblage density + as.factor(species identity)). 


\section{Results}

Fish assemblage variation along the UDG

Species richness increased from 3 to 12 , and density of individuals ranged between 0.10 and 1.69 (individuals $\mathrm{m}^{-2}$ ) along the UDG. Species richness and density within the assemblages were not significantly correlated (rho $=-0.32$, Spearman's correlation). Density was not significantly correlated to the UDG (rho $=-$ 0.46, Spearman's correlation), whereas species richness was strongly and positively linked to the UDG (linear model, $\mathrm{p}$-value $\left.<0.001, \mathrm{R}^{2}=0.71\right)$. Overall the composition of the fish assemblage did not exhibit a strong longitudinal pattern, as most species were present along most of the gradient (Fig. 4).

Effects of the UDG at the assemblage level: isotopic space area and path analysis

(Fig. 5, p-value $=0.014, \mathrm{R}^{2}=0.47$ ).

The path coefficients of UDG $\rightarrow$ species richness and UDG $\rightarrow$ isotopic space area relationships were both significant and positive (p-values $<0.001$ ). The path coefficient of species richness $\rightarrow$ isotopic space area relationship was also significant but negative $(\mathrm{p}$-value $=0.002)$. Path coefficients for the relationships including assemblage density were not significant (Fig. 6).

Effects of the UDG at the species level: changes in the niche overlap value $=0.204$, Kruskal-Wallis rank sum test). The linear model combining the three variables - UDG, species richness and species identity - was significant $(\mathrm{p}$-value $=0.006$, minimization of the Akaike's information criterion AIC) and explained as much as $70 \%$ of the isotopic niche overlap variations. The UDG seemed to

227 decrease the overlap, whereas assemblage species richness increased the overlap (Table 3). The effect of fish

228 species identity was exclusively driven by three species (p-value $<0.050$, Table 3): Phoxinus phoxinus, $P$. 229 pungitius, and Leuciscus leuciscus. The three species were rarely found within our 12 sites (Table 2), and we deduced that species identity was not an important factor acting on the variations of the isotopic niche overlap in

231 our study. Neither was the density of individuals within the assemblage, because the model was not improved by adding this factor as a new variable (non-significant effect and greater AIC). 


\section{Discussion}

\section{Structural and/or functional effects of the UDG}

Our goals consisted in examining the influence of the UDG on a temperate stream food web, and in clarifying the nature (i.e. structural or functional) of this effect.

We first found that the UDG had a structural effect on the food webs. Three potential mechanisms induce a modification of food web structure: a change in species richness, a change in density of individuals or a change in species identity. In our case the structural change was mainly due to a change in species richness. In accordance with previous patterns observed for both temperate (Oberdorff et al. 1993) and tropical streams (Ibañez et al. 2007; Winemiller et al. 2011), we observed that species richness increased along the UDG. Concerning the density of individuals, we did not observe any relationship between density and the UDG, suggesting that the assemblage structure variation along the UDG was not related to density. Last, we observed that most species were spread over all sampled sites, suggesting a weak longitudinal pattern in fish species identity.

We also found that the UDG had a functional effect on the food webs (both isotopic metrics exhibited an upstream-downstream pattern), confirming the key role of the longitudinal gradient in ecosystem functioning (Winemiller et al. 2011; Chang et al. 2012). Using a path analysis, we determined that this functional modification was related to two antagonistic influences of the UDG: (1) a direct influence modifying the linkages among the web members and leading to an increase in the isotopic space area, and (2) an indirect influence generated by its structural effect (increase in species richness) leading to a decrease of the isotopic space area. The direct effect predominated, so that the total effect of the UDG induced a general increase in the isotopic space area.

\section{A hypothesis-testing framework to determine the dominant feeding strategy of the assemblage}

After having determined the nature of the UDG effect on the food webs, we tried to clarify which feeding strategies of the fish could best explain the functional food web modifications. Following the proposed hypothesis-testing framework (Fig. 1), we took advantage of our double approach at two levels of organisation (i.e. assemblage and species levels), and compared the results of both isotopic metrics (i.e. the isotopic space area, and the isotopic niche overlap). Concerning the direct effect of the UDG on the functional features of the web, the isotopic space area increased while the isotopic niche overlap decreased from upstream to downstream. Taken together, the results matched only one feeding strategy of the framework: the "specialist" strategy (Fig. 1), 
263 indicating a specialisation of most individuals on a specific narrow range of diet items. For the indirect effect of

264 the UDG (i.e. via species richness), the isotopic space area decreased, and the isotopic niche overlap increased

265 when species richness increased. In the hypothesis-testing framework this matched only one feeding strategy: the

266 “type A generalist" strategy (Fig. 1), meaning that most of the individuals tended to adopt an opportunistic

267 feeding strategy, taking a similar wide range of diet items.

268 We propose several hypotheses to explain the different feeding strategies adopted by the fish

269 assemblage that could be tested with further experiments. The diet specialisation associated with the direct effect

270 of the UDG can be explained by two non-exclusive reasons. First, temperate streams are known to be more

271 stable from upstream to downstream (e.g. Sabo et al. 2010). Consequently, fish undergo less perturbation stress,

272 and their energy requirements should decrease along the UDG. With lower energetic demands fish omnivory

273 tends to decrease, and diet specialisation to increase (Arim et al. 2010). Second, downstream reaches are known

274 to display higher habitat heterogeneity, offering higher resource diversity (Ibañez et al. 2009). Fish could exploit

275 this larger range of available resources to focus on preferential food items corresponding to their optimal feeding

276 requirement (optimal foraging theory, MacArthur and Pianka 1966). In such cases the increase in habitat

277 heterogeneity along the UDG should lead to an increase in diet specialisation.

278 The opportunistic feeding strategy related to the indirect effect of the UDG (via structural changes) was

279 more unexpected. Generally an increase in species richness is associated with a species specialisation on

280 different trophic niches to reduce competition (niche segregation phenomenon due to the exclusion principle:

281 Gause 1934; Mason et al. 2008). In our case, the contrary happened: the increase in species richness led all

282 individuals to share a similar wide range of resources (high niche overlap and trophic redundancy). We explain

283 this unexpected strategy with a limitation of the available resources. As stated by Matthews (in Fig 9.1., p 459,

284 1998) resource scarcity makes individuals feed on every possible food items (including previously unused

285 resources) to meet their energy requirements (Araújo et al. 2011). In our case, resource scarcity could occur if

286 species richness increases faster than resource availability. 


\section{Conclusion}

In this study we show that the upstream-downstream gradient has a complex influence on temperate stream food webs. Its effect concerns both structural and functional features of the webs. From upstream to downstream, the structural modifications of the webs are mainly related to species richness, while the functional modifications are due to a direct and an indirect effect (via species richness) of the UDG. We link the direct effect of the UDG with a diet specialisation of the species, whereas the indirect effect seems related to a "type A generalist" feeding strategy.

We intentionally chose to address our issue with a relatively small catchment $\left(937 \mathrm{~km}^{2}\right)$, because it

295 allowed controlling for environmental factors and isotope baseline variation (see Online Resource 1). The other 296 side of the coin is that we only considered a relatively small portion of the UDG, and that our results now need 297 to be confirmed at a larger spatial scale. Anyway, we demonstrate that the UDG influences the functioning of 298 stream food web. Consequently, integrating the UDG should be a prerequisite for all studies dealing with stream 299 food webs, and future work should at least ensure, before making comparisons among food webs, that the 300 different studied sites are situated in a constrained part of the gradient (i.e. similar order of magnitude for 301 catchment area, stream width...). We also highlight the benefit of conducting a double approach at both assemblage and species levels

303 with two appropriate isotopic metrics (i.e. isotopic space area and isotopic niche overlap). Discriminating the 304 three potential feeding strategies is indeed not possible using only one metric. When applying the double 305 approach it must be kept in mind that the metrics are based on stable isotope analysis. Their interpretation in the 306 proposed framework should be done with caution in light of isotope limitations (Hoeinghaus and Zeug 2008;

307 Syväranta et al. 2013). For instance, the isotopic variability of the basal resources must be considered as a 308 potential confounding factor. Food web modifications can be related to both structural and functional features of the web. The study

310 of the interactions between these two features has key ecological implications in term of conservation and 311 management strategy, as directly related to the critical issue of linking structural and functional biodiversity 312 (Thompson et al. 2012). Our double approach (at assemblage and species level) provides a new hypothesis313 testing framework for exploring the feeding strategies underlying food web modifications, and can help in 314 understanding the interactions between both kinds (structural or functional) of modifications. 


\section{Acknowledgement}

316 Grateful acknowledgment is expressed to HEF team (part of Hydrosystems and Bioprocesses Research

317 Unit at Irstea Antony) for assistance in the field and sample preparation. We thank Adrien Rey and the regional

318 natural park "Parc Naturel Régional de la haute vallée de Chevreuse" for advice and participation to field work.

319 Olivier Delaigue gave helpful recommendations for statistical analyses. Michel Hénin, head of the RGIS

320 department at the "Institut d'Aménagement et d'Urbanisme d'île-de-France" kindly provided the land cover data.

321 We thank the anonymous reviewers, who helped improve the previous versions of this manuscript. This work

322 was partly funded by the Interdisciplinary Research Program on the Seine River Environment (PIREN-Seine -

323 http://www.sisyphe.upmc.fr/piren/) and by the project 33 of the framework agreement between Irstea and the

324 French National Agency for Water and Aquatic Environments (ONEMA). 


\section{References}

A.F.S. (American_Fisheries_Society), A.I.o.F.R.B. (American_Institute_of_Fishery_Research_Biologists), A.S.o.I.a.H. (American_Society_of_Ichtyologists_and_Herpetologists). Guidelines for the Use of Fishes in Research. American Fisheries Society, Bethesda, MA, 2004.

Araújo M, Bolnick D, Layman C (2011) The ecological causes of individual specialisation. Ecol Lett 14:948958. doi:10.1111/j.1461-0248.2011.01662.x

Arim M, Abades S, Laufer G, Loureiro M, Marquet P (2010) Food web structure and body size: Trophic position and resource acquisition. Oikos 119:147-153. doi: 10.1111/j.1600-0706.2009.17768.x

Bearhop S, Adams C, Waldron S, Fuller R, Macleod H (2004) Determining trophic niche width: A novel approach using stable isotope analysis. J Anim Ecol 73:1007-1012. doi:10.1111/j.0021-8790.2004.00861.x

Belliard J, Boët P, Tales E (1997) Regional and longitudinal patterns of fish community structure in the Seine river basin, France. Environ Biol Fish 50:133-147. doi:10.1023/A:1007353527126

Chang HY, Wu SH, Shao KT, Kao WY, Maa CJ, Jan RQ, Liu LL, Tzeng CS, Hwang JS, Hsieh HL, Kao SJ, Chen YK, Lin HJ (2012) Longitudinal variation in food sources and their use by aquatic fauna along a subtropical river in taiwan. Freshw Biol 57:1839-1853. doi:10.1111/j.1365-2427.2012.02843.x

Costas N, Pardo I (2014) Isotopic variability in a stream longitudinal gradient: implications for trophic ecology. Aquat Sciences. doi:10.1007/s00027-014-0383-2

Gause G (1934) The struggle for existence. Williams and Wilkins, Baltimore, Maryland

Hammerschlag-Peyer CM, Yeager LA, Araújo MS, Layman CA (2011) A hypothesis-testing framework for studies investigating ontogenetic niche shifts using stable isotope ratios. PLoS ONE 6:e27104. doi:10.1371/journal.pone.0027104

Hette-Tronquart N, Mazeas L, Reuilly-Manenti L, Zahm A, Belliard J (2012) Fish fins as non-lethal surrogates for muscle tissues in freshwater food web studies using stable isotopes. Rapid Commun Mass Spectrom 26:1603-1608. doi: 10.1002/rcm.6265

Hoeinghaus D, Zeug S (2008) Can stable isotope ratios provide for community-wide measures of trophic structure? comment. Ecol 89:2353-2357. doi:10.1890/07-1143.1

Holt R (1996) Food webs: integration of patterns and dynamics. In: Temporal and spatial aspects of food web structure and dynamics. Chapman \& Hall, New York, pp 255-257

Ibañez C, Oberdorff T, Teugels G, Mamononekene V, Lavoué S, Fermon Y, Paugy D, Toham A (2007) Fish assemblages structure and function along environmental gradients in rivers of Gabon (Africa). Ecol Freshw Fish 16:315-334. doi:10.1111/j.1600- 0633.2006.00222.x

Ibañez C, Belliard J, Hughes R, Irz P, Kamdem-Toham A, Lamouroux N, Tedesco P, Oberdorff T (2009) Convergence of temperate and tropical stream fish assemblages. Ecograph 32:658-670. doi:10.1111/j.16000587.2008.05591.x

Jackson A, Inger R, Parnell A, Bearhop S (2011) Comparing isotopic niche widths among and within communities: Siber-stable isotope bayesian ellipses in R. J Anim Ecol 80:595-602. doi:10.1111/j.13652656.2011.01806.x

Jackson MC, Donohue I, Jackson AL, Britton JR, Harper DM, Grey J (2012) Population- level metrics of trophic structure based on stable isotopes and their application to invasion ecology. PLoS ONE 7:e31757. doi:10.1371/journal.pone.0031757 
Jepsen D, Winemiller K (2002) Structure of tropical river food webs revealed by stable isotope ratios. Oikos 96:46-55. doi:10.1034/j.1600-0706.2002.960105.x

Layman C, Arrington D, Montaña C, Post D (2007) Can stable isotope ratios provide for community-wide measures of trophic structure? Ecol 88:42-48. doi:10.1890/0012-9658(2007)88[42:CSIRPF]2.0.CO;2

Layman C, Araújo M, Boucek R, Hammerschlag-Peyer C, Harrison E, Jud Z, Matich P, Rosenblatt A, Vaudo J, Yeager L, Post D, Bearhop S (2012) Applying stable isotopes to examine food-web structure: An overview of analytical tools. Biol Rev 87:545-562. doi:10.1111/j.1469-185X.2011.00208.x

MacArthur RH, Pianka ER (1966) On optimal use of a patchy environment. Am Nat 100:603-609

MacGarvey D, Hughes R (2008) Longitudinal zonation of pacific northwest (U.S.A.) fish assemblages and the species-discharge relationship. Copeia 2:311-321. doi:10.1643/CE- 07-020

Mason N, Lanoiselée C, Mouillot D, Wilson J, Argillier C (2008) Does niche overlap control relative abundance in french lacustrine fish communities? A new method incorporating functional traits. J Anim Ecol 77:661-669. doi:10.1111/j.1365- 2656.2008.01379.x

Matthews W (1998) Patterns in Freshwater Fish Ecology. Kluwer Academic Publishers, Norwell

Minns CK (1995) Allometry of home range size in lake and river fishes. Can J Fish Aquat Sciences 52:14991508

Newsome S, Del Rio C, Bearhop S, Phillips D (2007) A niche for isotopic ecology. Front Ecol Environ 5:429436. doi:10.1890/1540-9295(2007)5[429:ANFIE]2.0.CO;2

Oberdorff T, Guilbert E, Lucchetta JC (1993) Patterns of fish species richness in the Seine river basin, France. Hydrobiol 259:157-167. doi:10.1007/BF00006595

Oberdorff T, Pont D, Hugueny B \& Chessel D (2001) A probabilistic model characterizing riverine fish communities of French rivers: a framework for environmental assessment. Freshw Biol 46:399-415. doi:10.1046/j.1365-2427.2001.00669.x

Oberdorff T, Pont D, Hugueny B, Porcher J (2002) Development and validation of a fish- based index for the assessment of 'river health' in France. Freshw Biol 47:1720- 1734. doi:10.1046/j.1365-2427.2002.00884.x

O’Neil B, Thorp J (2014) Untangling food-web structure in an ephemeral ecosystem. Freshw Biol 59:14621473. doi:10.1111/fwb.12358

Petts G, Calow P (1996) River Biota: Diversity and Dynamics. Blackwell Science, Oxford

Post D, Layman C, Arrington D, Takimoto G, Quattrochi J, Montaña C (2007) Getting to the fat of the matter: Models, methods and assumptions for dealing with lipids in stable isotope analyses. Oecologia 152:179-189. doi:10.1007/s00442-006-0630-x

Post D, Takimoto G (2007) Proximate structural mechanisms for variation in food-chain length. Oikos 116:775782. doi:10.1111/j.2007.0030-1299.15552.x

Power M, Dietrich W (2002) Food webs in river networks. Ecol Res 17:451-471. doi:10.1046/j.14401703.2002.00503.x

Rasmussen J, Trudeau V, Morinville G (2009) Estimating the scale of fish feeding movements in rivers using $\delta^{13} \mathrm{C}$ signature gradients. J Anim Ecol 78:674-685. doi:10.1111/j.1365-2656.2008.01511.x

Rice S, Greenwood M, Joyce C (2001) Tributaries, sediment sources, and the longitudinal organisation of macroinvertebrate fauna along river systems. Can J Fish Aquat Sciences 58:824-840. doi:10.1139/cjfas-58-4824 
Sabo J, Finlay J, Kennedy T, Post D (2010) The role of discharge variation in scaling of drainage area and food chain length in rivers. Science 330:965-967. doi:10.1126/science.1196005

Sedell J, Richey J, Swanson F (1989) The river continuum concept: a basis for the expected ecosystem behaviour of very large rivers? Can Spec Publ Fish Aquat Sciences 106:49-55

Semmens B, Ward E, Moore J, Darimont C (2009) Quantifying inter-and intra-population niche variability using hierarchical bayesian stable isotope mixing models. PLoS ONE 4. doi:10.1371/journal.pone.0006187

Syväranta J, Lensu A, Marjomäki T, Oksanen S, Jones R (2013) An empirical evaluation of the utility of convex hull and standard ellipse areas for assessing population niche widths from stable isotope data. PLoS ONE 8. doi:10.1371/journal.pone.0056094

Thompson R, Brose U, Dunne J, Hall R, Hladyz S, Kitching R, Martinez N, Rantala H, Romanuk T, Stouffer D, Tylianakis J (2012) Food webs: Reconciling the structure and function of biodiversity. Trends in Ecol and Evol 27:689-697. doi:10.1016/j.tree.2012.08.005

Tomanova S, Tedesco P, Campero M, Van Damme P, Moya N, Oberdorff T (2007) Longitudinal and altitudinal changes of macroinvertebrate functional feeding groups in neotropical streams: A test of the river continuum concept. Fundam Appl Limnol 170:233-241. doi:10.1127/1863-9135/2007/0170-0233

Townsend C, Hildrew A (1994) Species traits in relation to a habitat templet for river systems. Freshw Biol 31:265-275

Vander Zanden M, Rasmussen J (1999) Primary consumer $\delta^{13} \mathrm{C}$ and $\delta^{15} \mathrm{~N}$ and the trophic position of aquatic consumers. Ecol 80:1395-1404

Vannote R, Minshall G, Cummins K, Sedell J, Cushing C (1980) The river continuum concept. Can J Fish Aquat Sciences 37:130-137

Verneaux J, Schmitt A, Verneaux V, Prouteau C (2003) Benthic insects and fish of the doubs river system: Typological traits and the development of a species continuum in a theoretically extrapolated watercourse. Hydrobiol 490:63-74. doi:10.1023/A:1023454227671

Werner R, Brand W (2001) Referencing strategies and techniques in stable isotope ratio analysis. Rapid Commun Mass Spectrom 15:501-519. doi:10.1002/rcm.258

Winemiller K, Hoeinghaus D, Pease A, Esselman P, Honeycutt R, Gbanaador D, Carrera E, Payne J (2011) Stable isotope analysis reveals food web structure and watershed impacts along the fluvial gradient of a mesoamerican coastal river. River Res Appl 27:791-803. doi:10.1002/rra.1396

Wootton J (1994) Predicting direct and indirect effects: An integrated approach using experiments and path analysis. Ecol 75:151-165 
Table 1 Sites' description. Upstream catchment area, distance from the sources, and slope were calculated with the RGIS data. Stream width, water depth, current velocity, temperature and oxygen were measured once during October 2009 but not on the same day for all sites. This explains the slightly different temperatures and oxygen concentrations of sites 7 and 12

\begin{tabular}{|c|c|c|c|c|c|c|c|c|c|c|}
\hline Stream & Site code & $\begin{array}{c}\text { Upstream } \\
\text { catchment } \\
\text { area } \\
\end{array}$ & $\begin{array}{c}\text { Distance } \\
\text { from the } \\
\text { sources }\end{array}$ & Width & $\begin{array}{l}\text { Water } \\
\text { depth }\end{array}$ & Slope & $\begin{array}{l}\text { Current } \\
\text { velocity }\end{array}$ & Temperature & Oxygen & $\begin{array}{l}\text { Position on the } \\
\text { UDG }\end{array}$ \\
\hline & & $\left(\mathbf{k m}^{2}\right)$ & $(\mathbf{k m})$ & (m) & (m) & $(\mathbf{m} / \mathbf{m})$ & $(\mathbf{m} / \mathbf{s})$ & $\left({ }^{\circ} \mathbf{C}\right)$ & $(\mathrm{mg} / \mathrm{l})$ & $1^{\text {st }}$ PCA axis \\
\hline Rabette & 1 & 17 & 7.0 & 1.9 & 0.07 & 0.004 & 0.2 & 15.0 & 9.5 & -2.11 \\
\hline Aulne & 2 & 24 & 3.9 & 2.2 & 0.16 & 0.006 & 0.1 & 13.0 & 9.2 & -1.64 \\
\hline Yvette & 3 & 28 & 8.8 & 2.4 & 0.26 & 0.005 & 0.3 & 14.0 & 9.6 & -0.73 \\
\hline Vaux & 4 & 19 & 3.8 & 2.9 & 0.29 & 0.004 & 0.1 & 13.5 & 9.2 & -0.90 \\
\hline Aulne & 5 & 58 & 7.2 & 2.8 & 0.17 & 0.003 & 0.2 & 14.5 & 8.8 & -0.64 \\
\hline Yvette & 6 & 153 & 18.9 & 7.0 & 0.25 & 0.001 & 0.4 & 15.0 & 9.2 & 1.82 \\
\hline Rémarde & 7 & 178 & 19.6 & 6.5 & 0.39 & 0.002 & 0.1 & 8.8 & 10.8 & 2.49 \\
\hline Charmoise & 8 & 20 & 2.7 & 1.4 & 0.13 & 0.009 & 0.1 & 13.0 & 8.2 & -2.35 \\
\hline Prédecelle & 9 & 26 & 12.5 & 2.2 & 0.15 & 0.005 & 0.2 & 12.8 & 9.7 & -1.10 \\
\hline Renarde & 10 & 91 & 11.3 & 2.8 & 0.26 & 0.004 & 0.3 & 12.0 & 10.2 & 0.22 \\
\hline Orge & 11 & 115 & 24.2 & 4.5 & 0.44 & 0.003 & 0.1 & 12.0 & 9.6 & 2.36 \\
\hline Orge & 12 & 210 & 26.6 & 5.8 & 0.32 & 0.001 & 0.2 & 9.0 & 11.8 & 2.57 \\
\hline
\end{tabular}


Table 2 Species sampled from the Orge River catchment in summer 2009. Nbi is the total number of individuals caught by electrofishing, all sites taken together. $\mathrm{Nbs}$ is the number of the different sites where a given species was found. SIA is the number of fish whose stable isotope ratios were determined

\begin{tabular}{|c|c|c|c|c|c|}
\hline Common name & Scientific name & Species code & $\mathrm{Nbi}$ & $\mathrm{Nbs}$ & SIA \\
\hline Stone Loach & Barbatula barbatula & $\mathrm{Bab}$ & 562 & 12 & 198 \\
\hline Bullhead & Cottus gobio & $\operatorname{Cog}$ & 141 & 6 & 40 \\
\hline Stickleback & Gasterosteus aculeatus & Gaa & 18 & 6 & 9 \\
\hline Gudgeon & Gobio gobio & Gog & 189 & 7 & 83 \\
\hline Common dace & Leuciscus leuciscus & Lel & 12 & 1 & 6 \\
\hline Perch & Perca fluviatilis & Pef & 65 & 5 & 33 \\
\hline Minnow & Phoxinus phoxinus & Php & 62 & 2 & 25 \\
\hline Ninespine stickleback & Pungitius pungitius & Pup & 34 & 5 & 5 \\
\hline Roach & Rutilus rutilus & Rur & 45 & 5 & 36 \\
\hline Zander & Sander lucioperca & Sal & 2 & 2 & 1 \\
\hline Chub & Squalius cephalus & $\mathrm{Sqc}$ & 46 & 6 & 29 \\
\hline Freshwater Bream & Abramis brama & $\mathrm{Abb}$ & 1 & 1 & No \\
\hline European eel & Anguilla anguilla & Ana & 1 & 1 & No \\
\hline Crucian carp & Carassius carassius & $\mathrm{Cac}$ & 2 & 1 & No \\
\hline European brook lamprey & Lampetra planeri & Lap & 2 & 1 & No \\
\hline Pumpkinseed & Lepomis gibbosus & Leg & 6 & 1 & No \\
\hline Brown trout & Salmo trutta fario & Sat & 23 & 3 & No \\
\hline Rudd & Scardinius erythtophthalmus & Sce & 1 & 1 & No \\
\hline
\end{tabular}


Table 3 Parameters of the linear model combining - UDG, species richness and species identity - to explain the variations of the isotopic niche overlap. '*' indicates a significant effect, and '***' stands for a highly significant one. Species codes are given in Table2

\begin{tabular}{lrlc}
\hline Variable & Coefficient & p-value & \\
\hline (intercept) & -31.6 & 0.014 & $*$ \\
UDG & -7.9 & 0.037 & $*$ \\
Species richness & 8.3 & 0.0005 & $* * *$ \\
Bab & 0.0 & - & - \\
Cog & -4.0 & 0.710 & \\
Gaa & 20.2 & 0.246 & \\
Gog & 11.0 & 0.204 & \\
Lel & -40.3 & 0.037 & $*$ \\
Pef & -4.3 & 0.732 & \\
Php & 25.8 & 0.049 & $*$ \\
Pup & -48.2 & 0.015 & $*$ \\
Rur & 3.0 & 0.779 & \\
Sqc & -13.9 & 0.286 &
\end{tabular}


Fig. 1 Potential feeding strategies within an assemblage and expected patterns of the isotopic metrics (isotopic space area and niche overlap, abbreviated ISA and INO, respectively). Black dots represent individuals within a species. (1) If the assemblage is mostly composed of specialist species, individuals of a given species would be specialised on the same narrow range of resources (e.g. $\mathrm{P}_{1}$ ) with the same isotopic signal (e.g. $\delta_{\mathrm{P} 1}$ ), but individuals from different species would consume different resources and display different isotopic signals $\left(\delta_{\mathrm{P} 1}\right.$, $\delta_{\mathrm{P} 2}$, or $\delta_{\mathrm{P} 3}$ ). Consequently, the assemblage would occupy a large isotopic space area, but the niche overlap between species would be low. (2) In the case of an assemblage composed of type A generalist species, all individuals would consume a similar wide range of resources $(\overline{\mathrm{P}})$ and thus have similar isotopic signals $(\delta \overline{\mathrm{P}})$. This assemblage would occupy a small isotopic space area, but the niche overlap between species would be high. (3) Last, the assemblage could be mostly composed of type B generalist species. In this case, individuals of the same species would be specialised on different and narrow ranges of resources (e.g. $\mathrm{P}_{1}, \mathrm{P}_{2}$, or $\mathrm{P}_{3}$ ) displaying different isotopic signals $\left(\delta_{\mathrm{P} 1}, \delta_{\mathrm{P} 2}\right.$, or $\left.\delta_{\mathrm{P} 3}\right)$, but individuals from different species could share the same resource (e.g. $\mathrm{P}_{1}$ ) and have the same isotopic signal (e.g. $\delta_{\mathrm{P} 1}$ ). Consequently, the isotopic space area occupied by this assemblage would be large and the niche overlap between species would be high

Fig. 2 Map of the Orge river catchment showing the location of the 12 sample sites. See Table 1 for a short description of all sites

Fig. 3 Representation of isotopic niche overlap. The different polygons represent the isotopic niches occupied by six different species. The grey area is the niche area of species 3 that is occupied by the other species $(2,4$ and 5). Together with the whole niche area of species 3 , they give the niche overlap of species 3 . Here, species 1 has no niche overlap with other species

Fig. 4 Distribution of the fish species along the UDG according to their family. Each point indicates the presence of a species at a given site (12 sites per species maximum). Species codes are given in Table 2. The site position along the UDG is given by a multivariate index that increases from upstream to downstream

Fig. 5 Influence of the UDG on the isotopic space area: a significant linear model is found (black line). Dashed lines represent the confidence limits of the model at the 0.95 level $\left(p=0.012, R^{2}=0.48\right)$

Fig. 6 Results of the path analysis quantifying the relationships between the UDG, species richness, and density of individuals within the assemblage. Solid lines indicate significant paths and dashed lines indicate not significant paths. Numbers are path coefficients

Online Resource 1 Isotopic variations in basal resources along the UDG 


Species
Resources
for ind. of $\mathrm{S} 1, \mathrm{~S} 2$ and $\mathrm{S} 3$, respectively
ISA




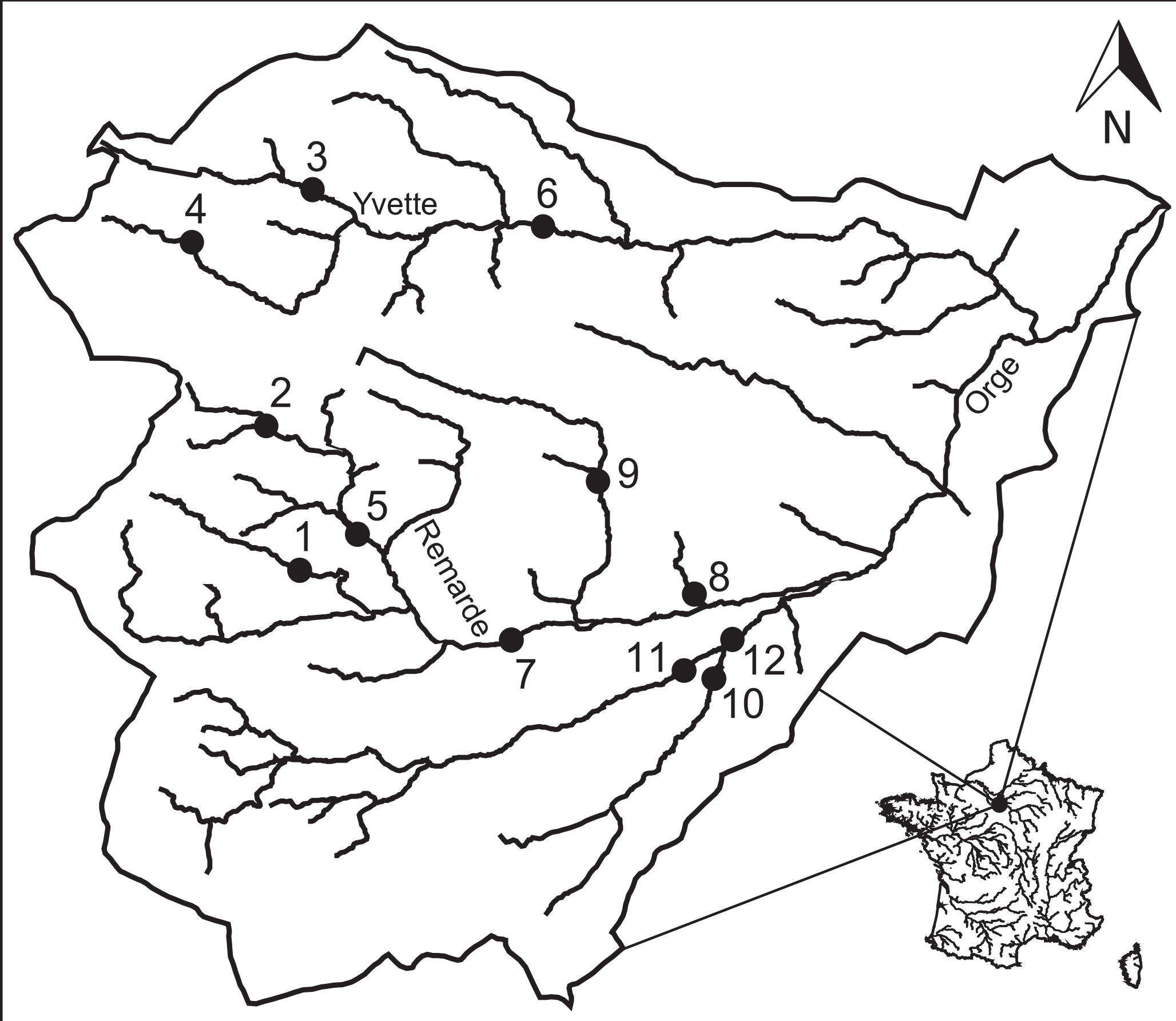

- Streams

- Study sites

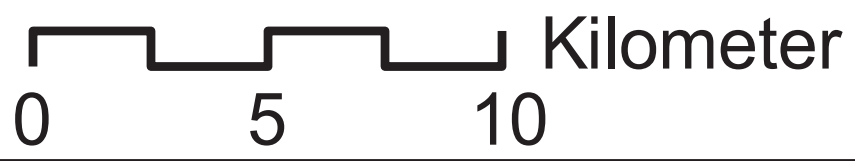




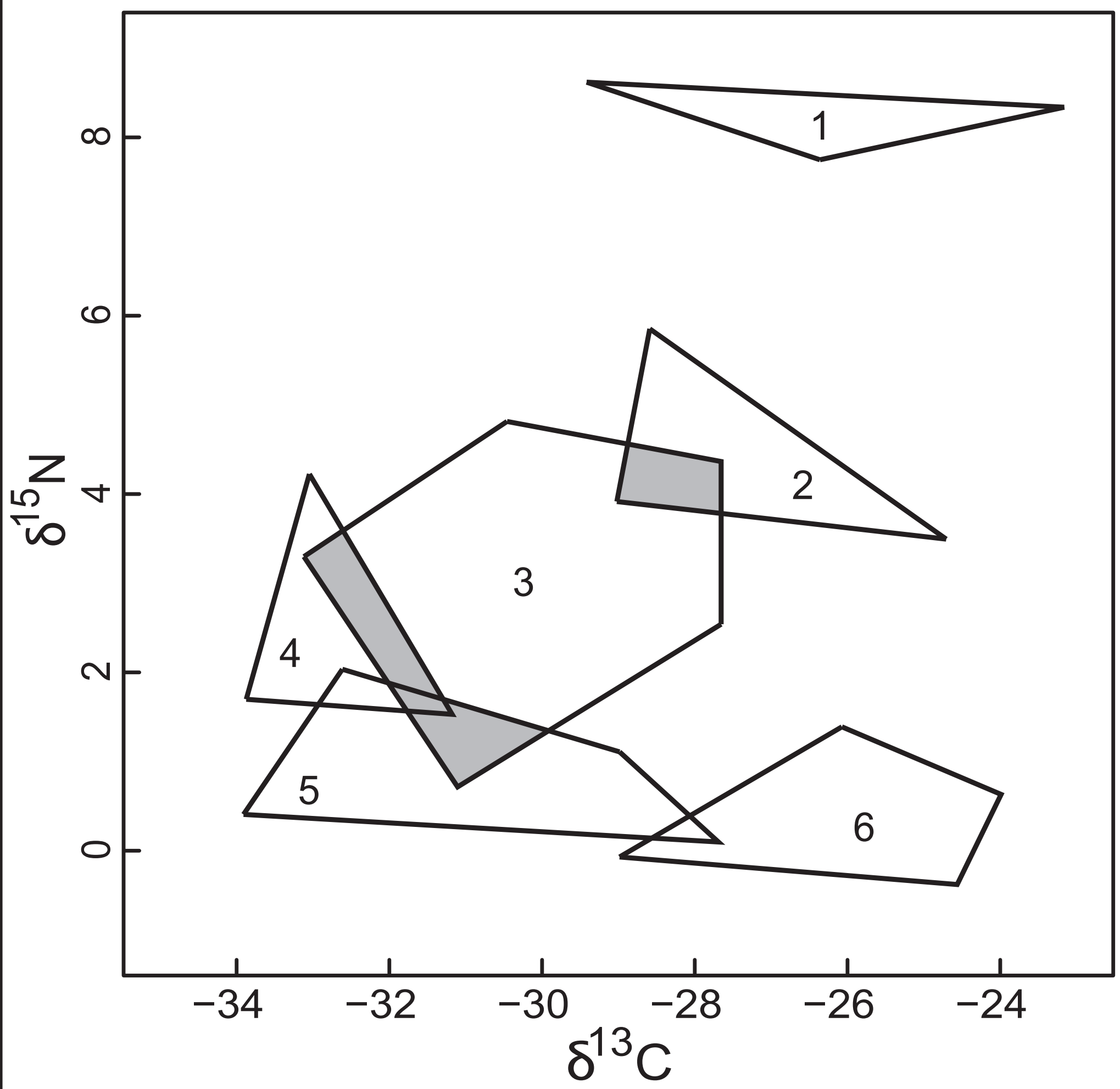


Petromyzontidae

Lap

Anguillidae

Ana

Cyprinidae

Nemacheilidae

Lel
Php
Sce
Gog
Rur
Sqc
Cac
Abb

$\mathrm{Bab}$

Salmonidae

Cottidae

Sat

Percidae

Cog

Sef

Centrarchidae

Leg

Gasterosteidae

Pup

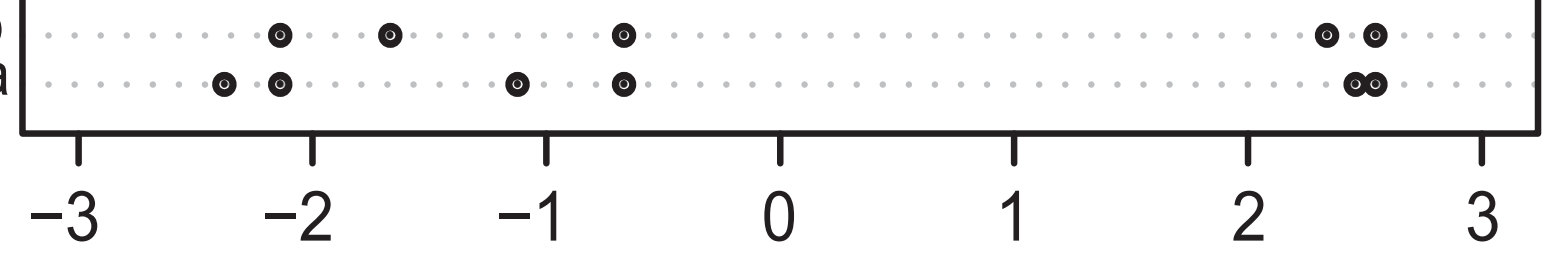

Position along the UDG 


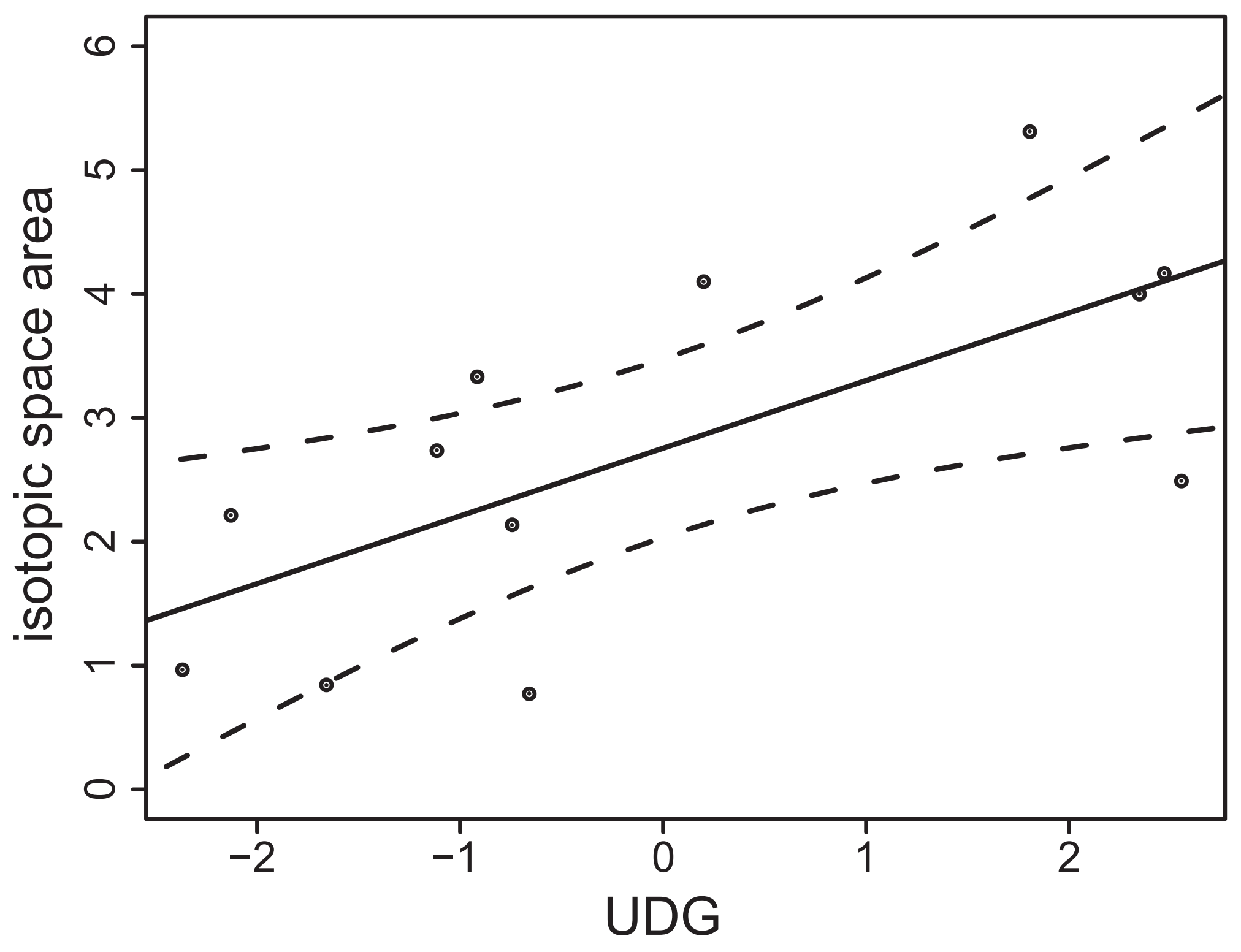




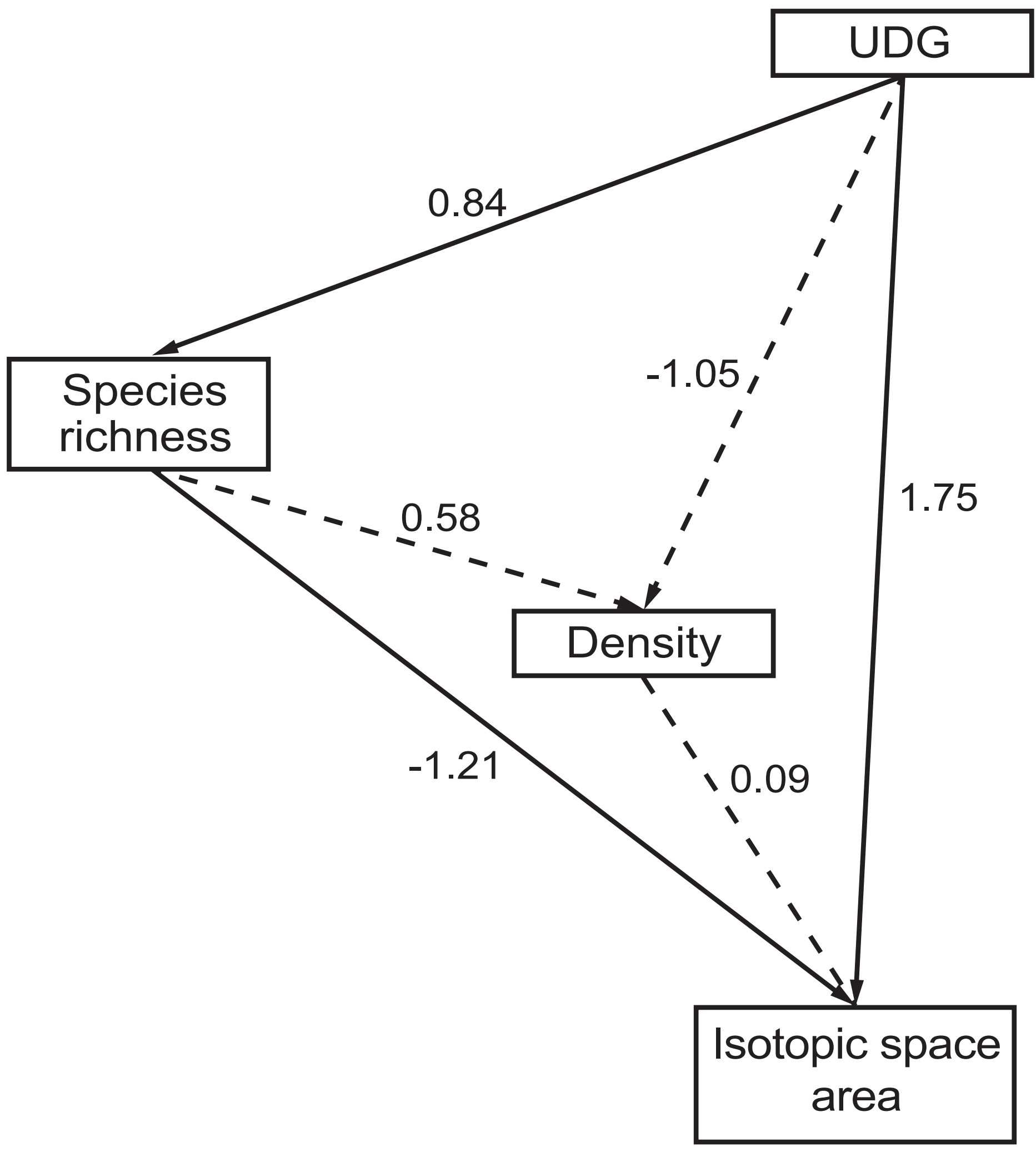




\title{
Isotopic variations in basal resources along the Upstream-Downstream Gradient (UDG)
}

\author{
Online resource of the article: Stable isotopes reveal food web modifications \\ along the upstream-downstream gradient of a temperate stream
}

\author{
Aquatic Sciences
}

\author{
Hette-Tronquart N, Belliard J, Tales E, Oberdorff T
}

Correspondence to : Nicolas Hette-Tronquart, UR HBAN - Irstea

nicolas.hette@edu.mnhn.fr

Context The variability of the isotopic signals within a food web depends on the diversity of resources available at the base of the food web, and on the isotopic variability among the different food items (Matthews and Mazumder 2004). As a result, an increase of the isotopic variability in the food web does not necessarily mean that the diversity of the resources consumed by the web increases; it can also be the result of a greater isotopic variability within the same set of resources.

In our study, we find that the isotopic space area increases along the UDG, and before interpreting the result we checked if the isotopic variability at the resource level contributed to the increase of the isotopic space area. We first examined if the isotopic variation in basal resources increased along the UDG. For this, we took advantage of the carbon and nitrogen isotope signals of three basal resources : epilithic biofilm, leaf litter and suspended matter.

Method Three independent samples of each source of organic matter were collected at each site approximately one month before fish sampling occurred. Biofilms were collected by gently brushing stones found in the river with a toothbrush; leaf litter sample consisted in old leaves decomposing in the stream; and suspended matter were obtained by 
filtering stream water on glass fiber filter $(\varnothing=0.7 \mu \mathrm{m})$. Leaf litter samples were rinsed with distilled water at laboratory, before being freeze-dried like the biofilm and suspended matter samples. Samples were ground to powder if necessary, weighed in tin capsules and analysed with EA-IRMS following the same method than fish samples (see "stable isotope analysis SIA" section in the "Material and Methods" part). We evaluated the mean isotope signal of each source for carbon and nitrogen using the isotope ratios of the three independent samples (see Table A1). Based on the average values, we determined the isotopic variability in basal resources calculating the range of the signals at each site for both carbon and nitrogen. We tested if the isotopic variation in basal resources increases from upstream to downstream, calculating Spearman's rank correlation coefficients between the range of the isotope signals and the UDG for both carbon and nitrogen.

Table A1 - Carbon and nitrogen isotope ratios of three basal resources. For each source, three independent samples were collected at each site

\begin{tabular}{|c|c|c|c|c|c|c|c|c|c|c|}
\hline \multirow{2}{*}{$\begin{array}{l}\text { Site } \\
\text { code }\end{array}$} & & \multicolumn{3}{|c|}{ leaf litter } & \multicolumn{3}{|c|}{ epilithic biofilm } & \multicolumn{3}{|c|}{ suspended matter } \\
\hline & & 1 & 2 & 3 & 1 & 2 & 3 & 1 & 2 & 3 \\
\hline 1 & & -30.4 & -29.6 & -29.6 & -26.9 & -26.3 & -27.4 & -28.4 & -28.3 & -28.4 \\
\hline 2 & & -28.5 & -29.5 & -28.6 & -29.2 & -28.7 & -29.2 & -28.6 & -28.7 & -28.5 \\
\hline 3 & & -28.9 & -29.5 & -29.6 & -33.9 & -33.3 & -33.1 & -29.1 & -29.3 & -29.5 \\
\hline 4 & & -28.1 & -28.7 & -28.9 & -26.9 & -28.8 & -29.6 & -28.8 & -29.0 & -28.9 \\
\hline 5 & & -28.8 & -27.6 & -30.5 & -29.6 & -29.4 & -29.1 & -28.3 & -28.4 & -28.5 \\
\hline 6 & $m_{m}^{u}$ & -27.4 & -29.7 & -29.8 & -34.1 & -33.2 & -31.3 & -28.9 & -28.7 & -29.1 \\
\hline 7 & io & -30.1 & -31.7 & -29.5 & -22.8 & -20.3 & -18.5 & -28.2 & -28.4 & -28.3 \\
\hline 8 & & -29.7 & -29.4 & -28.7 & -27.5 & -27.7 & -27.1 & -27.9 & -27.7 & -27.8 \\
\hline 9 & & -29.1 & -29.0 & -29.6 & -27.1 & -30.6 & -31.7 & -26.2 & -27.8 & -28.1 \\
\hline 10 & & -28.3 & -29.2 & -29.5 & -28.3 & -30.2 & -21.4 & -25.9 & -25.8 & -26.0 \\
\hline 11 & & -27.3 & -28.7 & -26.1 & -26.4 & -25.9 & -26.3 & -27.9 & -27.8 & -27.9 \\
\hline 12 & & -31.0 & -29.3 & -27.4 & -28.3 & -28.2 & -27.6 & -28.0 & -27.6 & -27.7 \\
\hline 1 & & 0.6 & 0.9 & 1.7 & 3.5 & 3.1 & 3.3 & 2.8 & 3.0 & 3.0 \\
\hline 2 & & -0.1 & 1.5 & -0.2 & -0.2 & -0.6 & 1.5 & 2.2 & 2.9 & 2.2 \\
\hline 3 & & -1.7 & 0.7 & 2.1 & 12.9 & 11.6 & 13.0 & 5.8 & 5.8 & 6.0 \\
\hline 4 & & 4.3 & 2.5 & 3.6 & 7.4 & 5.8 & 6.0 & 4.1 & 4.5 & 4.7 \\
\hline 5 & & 0.9 & 1.1 & 0.6 & 5.6 & 5.6 & 8.5 & 4.8 & 4.2 & 4.5 \\
\hline 6 & $z$ & 3.9 & 2.8 & 3.3 & 7.3 & 8.6 & 10.9 & 6.3 & 6.9 & 6.4 \\
\hline 7 & مै & 1.8 & 1.9 & 5.3 & 6.6 & 5.8 & 5.2 & 6.4 & 6.2 & 6.4 \\
\hline 8 & & 2.4 & 2.1 & 2.7 & 7.1 & 6.7 & 5.8 & 7.7 & 7.6 & 8.0 \\
\hline 9 & & -0.6 & -0.5 & 1.2 & 4.7 & 4.5 & 4.7 & 5.3 & 4.9 & 5.6 \\
\hline 10 & & 1.5 & -0.2 & 0.5 & 5.0 & 4.7 & 4.8 & 3.9 & 4.0 & 4.3 \\
\hline 11 & & 0.6 & 3.0 & 0.7 & 6.2 & 5.3 & 6.8 & 4.2 & 4.5 & 4.4 \\
\hline 12 & & -0.7 & -0.8 & 0.6 & 5.1 & 4.7 & 6.5 & 4.9 & 5.1 & 5.4 \\
\hline
\end{tabular}

Result and Conclusion Results of both correlation tests (see Table A2) show that there are no correlation between the isotopic variability in basal resources and the UDG. We can confidently deduce that the isotopic variability at the resource level does not 
contribute to the increase of the isotopic space area. Consequently, the diversity of the exploited resources shall be the main reason why the isotopic space area increases from upstream to downstream.

Table A2 - Results of the two Spearman's correlation tests between the range of the resource isotope ratios (calculated with the mean signals of each source) and the UDG

\begin{tabular}{c|cc}
$\begin{array}{c}\text { Spearman's correlation test } \\
\text { between UDG and... }\end{array}$ & rho coefficient & p-value \\
\hline carbon isotopic range & 0.24 & 0.444 \\
nitrogen isotopic range & 0.35 & 0.266
\end{tabular}

\section{Références}

Matthews B, Mazumder A (2004) A critical evaluation of intrapopulation variation of $\delta^{13} \mathrm{C}$ and isotopic evidence of individual specialization. Oecologia $140: 361-371$. 